\title{
Butyricicoccus pullicaecorum gen. nov., sp. nov., an anaerobic, butyrate-producing bacterium isolated from the caecal content of a broiler chicken
}

\author{
Correspondence \\ Venessa Eeckhaut \\ venessa.eeckhaut@UGent.be
}

\author{
Venessa Eeckhaut, ${ }^{1}$ Filip Van Immerseel, ${ }^{1}$ Emma Teirlynck, ${ }^{1}$ \\ Frank Pasmans, ${ }^{1}$ Veerle Fievez, ${ }^{2}$ Cindy Snauwaert, ${ }^{3}$ \\ Freddy Haesebrouck, ${ }^{1}$ Richard Ducatelle, ${ }^{1}$ Petra Louis ${ }^{4}$ \\ and Peter Vandamme ${ }^{3}$
}
${ }^{1}$ Department of Pathology, Bacteriology and Avian Diseases, Research Group Veterinary Public Health and Zoonoses, Faculty of Veterinary Medicine, Ghent University, Salisburylaan 133, B- 9820 Merelbeke, Belgium
${ }^{2}$ Laboratory for Animal Nutrition and Animal Product Quality, Ghent University, Proefhoevestraat 10, B-9090 Melle, Belgium
${ }^{3}$ Laboratory of Microbiology, Ghent University, K. L. Ledeganckstraat 35, B-9000 Ghent, Belgium
${ }^{4}$ Microbial Ecology Group, Rowett Research Institute, Greenburn Road, Bucksburn, Aberdeen AB21 9SB, UK

\begin{abstract}
Five isolates that produced large amounts of butyrate were obtained in the course of a study on the butyrate-producing microbiota from the caecal content of a 4-week-old broiler chicken. The five isolates were virtually indistinguishable in biochemical and genetic terms, suggesting that they were derived from a single bacterial clone colonizing this habitat. A phylogenetic analysis based on 16S rRNA gene sequences demonstrated that the five isolates represented a unique lineage within the Clostridium leptum subgroup of the clostridia, with Eubacterium desmolans as the closest phylogenetic neighbour (about 93\% similarity). These data indicate that the five novel isolates represent a single novel species within a novel genus, for which we propose the name Butyricicoccus pullicaecorum gen. nov., sp. nov. The type strain of Butyricicoccus pullicaecorum is $25-3^{\top}\left(=\right.$ LMG $24109^{\top}=$ CCUG $\left.55265^{\top}\right)$. The DNA G $+C$ content of strain $25-3^{\top}$ was $54.5 \mathrm{~mol} \%$.
\end{abstract}

In broiler chickens, the gastrointestinal tract harbours numerous bacterial species, of which only $10 \%$ have been characterized: $35 \%$ represent previously unknown species within a known bacterial genus and the remaining $55 \%$ represent bacteria for which even genus allocation is not possible (Apajalahti et al., 2004). A study of the microbiota of chicken caeca conducted by Lan et al. (2002) showed the predominance $(94 \%)$ of sequences from within the phylum Firmicutes, the most abundant sequences belonging to the Clostridium coccoides subgroup and the Clostridium leptum subgroup (Collins et al., 1994). Both subgroups contain numerous members that are known to produce butyrate as a product of fermentation (Pryde et al., 2002). There is increased interest in butyrate-producing

The GenBank/EMBL/DDBJ accession number for the 16S rRNA gene sequence of strain $25-3^{\top}$ is EU410376.

RAPD and REP-PCR genomic patterns and a scanning electron micrograph of cells of strain $25-3^{\top}$ are available as supplementary figures with the online version of this paper. strains in the context of veterinary medicine, because butyrate reduces invasion and colonization by Salmonella and stimulates intestinal epithelial cell growth (Van Immerseel et al., 2005; Kien et al., 2007). To our knowledge, butyrate-producing bacteria belonging to the phylum Firmicutes have not been isolated from the chicken gastrointestinal tract to date.

Bacteria were obtained from the caecal content of a 4week-old broiler chicken that had been given a wheatbased, commercial, broiler feed supplemented with $2 \%$ fructo-oligosaccharides (Orafti) from week 3 . The chicken was euthanized and a sample of the caecal content was homogenized in anaerobic M2GSC medium (Miyazaki et al., 1997) as described by Barcenilla et al. (2000). Tenfold serial dilutions of this suspension were made and, from each dilution, $0.3 \mathrm{ml}$ was spread onto agar plates containing M2GSC medium with $1.5 \%$ agar. The plates were incubated at $42{ }^{\circ} \mathrm{C}$, which is similar to the body temperature of poultry (Richards, 1970), for $48 \mathrm{~h}$ and 
then 58 single colonies were transferred to tubes containing M2GSC broth $(10 \mathrm{ml})$. All manipulations were performed in an anaerobic workstation (Ruskinn Technology). Shortchain fatty acid concentrations in overnight cultures were analysed using GLC (GC14; Shimadzu) as described by Van Nevel \& Demeyer (1977). Several butyrate-producing cultures were obtained. The supernatants of five of these bacterial cultures, i.e. ones obtained using isolates 11-3, 25$3^{\mathrm{T}}, 44-3,49-3$ and 54-3, contained more than $13 \mathrm{mM}$ butyric acid. These isolates were characterized in detail.

Repetitive-element-primed PCR with the (GTG) $)_{5}$ primer and randomly amplified polymorphic DNA typing using two distinct primers (5'-TGCGCGCGGG-3' and $5^{\prime}$ AGCGGGCCAA-3') were performed as described previously (Versalovic et al., 1994; Coenye et al., 2002) after DNA extraction with an alkaline lysis procedure. The isolates yielded identical, or virtually identical, DNA fingerprints in all three assays (see Supplementary Figs S1 and S2, available in IJSEM Online), suggesting that all five originate from a single strain that colonized the intestinal tract of the sampled chicken.

To elucidate the phylogenetic position of the five isolates, almost-complete $16 \mathrm{~S}$ rRNA gene sequences (corresponding to positions 8-1541 in the Escherichia coli numbering system) were determined for each isolate by using the 'universal' eubacterial primers $\mathrm{fD} 1$ and $\mathrm{rD} 1$ (Weisburg et al., 1991). The purified amplicons were sequenced using the BigDye Terminator sequencing kit with primers $\mathrm{pD}$, Gamma $^{*}, 3$ and $\mathrm{O}^{*}$ on an ABI PRISM 310 Genetic Analyzer (Coenye et al., 1999). The closest match to the deduced sequences was found using the FASTA program (Pearson \& Lipman, 1988). The nucleotide sequences were aligned with reference $16 \mathrm{~S}$ rRNA gene sequences by using the CLUSTAL W program (Thompson et al., 1994) and a phylogenetic tree was constructed using the neighbourjoining method (Saitou \& Nei, 1987) via the PHYLIP package (Felsenstein, 1989), using DNADIST for distance analysis (Kimura, 1980) (Fig. 1).

Fig. 1 shows the phylogenetic position of the five isolates among their closest relatives, i.e. members of the C. leptum subgroup. The isolates shared virtually identical (98-99\%) $16 \mathrm{~S}$ rRNA gene sequences and were most closely related to a butyrate-producing bacterium from the human gut (Barcenilla et al., 2000) (94\% sequence similarity) and to Eubacterium desmolans ATCC $43058^{\mathrm{T}}$ (Morris et al., 1986) (93\%).

Determination of the genomic DNA G $+C$ content of isolate $25-3^{T}$ was performed by using a Waters Breeze HPLC system and an XBridge Shield RP18 column maintained at $37^{\circ} \mathrm{C}$. This gave a value of $54.5 \mathrm{~mol} \%$.

All five isolates comprised Gram-positive coccoid cells that were $1.2-1.5 \mu \mathrm{m}$ long. A scanning electron micrograph of isolate $25-3^{\mathrm{T}}$ is shown in Supplementary Fig. S3. Following overnight incubation on M2GSC medium at $42{ }^{\circ} \mathrm{C}$, colonies were white in colour and $1-2 \mathrm{~mm}$ in diameter.

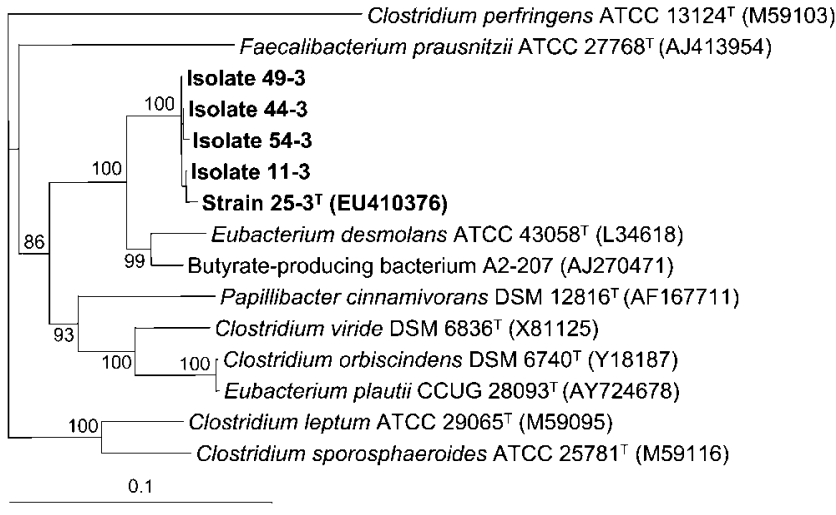

Fig. 1. Phylogenetic tree, based on $16 \mathrm{~S}$ rRNA gene sequences, showing the five butyrate-producing isolates and members of the C. leptum subgroup. The tree was constructed using the neighbour-joining method and was based on a comparison of approximately 1360 nt. Numbers at nodes are bootstrap percentages (based on 100 resamplings); values $<80 \%$ are not shown. The 16S rRNA gene sequence of Clostridium perfringens ATCC $13124^{\top}$ was used as an outgroup. Bar, 0.1 substitutions per nucleotide position.

Characterization of the biochemical properties of the strains was done using the commercially available API 20A microtest system (bioMérieux) according to the manufacturer's instructions, except that incubation was performed at $42{ }^{\circ} \mathrm{C}$ instead of $36 \pm 2{ }^{\circ} \mathrm{C}$. All five isolates showed hydrolysis of aesculin and fermentation of glucose, salicin, sucrose, maltose, xylose, cellobiose, mannose and trehalose. No urease activity was detected and hydrolysis of gelatin and fermentation of mannitol, lactose, arabinose, glycerol, melezitose, raffinose, sorbitol and rhamnose were absent. The ability of the isolates to degrade starch was determined by culturing them on M2GSC agar, which contains $0.2 \%$ starch. After overnight anaerobic incubation at $42{ }^{\circ} \mathrm{C}$, the plates were flooded with a commercial Lugol solution (Sigma). Clear zones around areas of cell growth indicated hydrolysis of starch.

When plates inoculated with isolate $25-3^{\mathrm{T}}$ were exposed to air for more than $3.5 \mathrm{~h}$, subsequent anaerobic growth seemed to be prevented. The isolates produced more than $13 \mathrm{mM}$ butyrate and utilized acetate; three out of the five isolates consumed small amounts of propionate. Four strains were also tested for $\mathrm{H}_{2}$ and $\mathrm{CO}_{2}$ production. For this purpose, $1 \mathrm{ml}$ gas phase was sampled with a gas-tight syringe and analysed for $\mathrm{H}_{2}$ and $\mathrm{CO}_{2}$ (FM Dual Column GC 700; Avondale) (Van Nevel et al., 1970) (Table 1).

In conclusion, in the course of a study on the butyrateproducing microbiota from the caecal content of a 4-weekold broiler chicken, five isolates were obtained that produced large amounts of butyrate in overnight cultures of M2GSC broth. The five isolates were virtually indistinguishable in biochemical and genetic terms, suggesting that they were derived from a single bacterial clone colonizing 
Table 1. Fermentation products of the five caecal isolates

The isolates were grown overnight in M2GSC broth at $42{ }^{\circ} \mathrm{C}$. Concentrations $(\mathrm{mM})$ are means of three replications $( \pm \mathrm{SD})$. ND, Not done.

\begin{tabular}{|lllccc|}
\hline Isolate & Acetate & Propionate & Butyrate & $\mathbf{H}_{\mathbf{2}}$ & $\mathbf{C O}_{\mathbf{2}}$ \\
\hline $11-3$ & $-10.6 \pm 4.3$ & $-0.6 \pm 1.1$ & $13.2 \pm 1.0$ & $\mathrm{ND}$ & $\mathrm{ND}$ \\
$25-3^{\mathrm{T}}$ & $-14.3 \pm 1.7$ & $-1.4 \pm 1.2$ & $18.6 \pm 1.2$ & $6.6 \pm 0.3$ & $16.5 \pm 4.7$ \\
$44-3$ & $-14.6 \pm 3.5$ & $-1.1 \pm 0.3$ & $15.5 \pm 4.3$ & $7.9 \pm 0.9$ & $17.7 \pm 1.2$ \\
$49-3$ & $-12.4 \pm 0.7$ & $-0.7 \pm 0.4$ & $18.6 \pm 5.1$ & $7.1 \pm 0.7$ & $13.6 \pm 2.8$ \\
$54-3$ & $-11.8 \pm 5.9$ & $-0.2 \pm 0.9$ & $13.6 \pm 0.2$ & $5.8 \pm 1.8$ & $15.6 \pm 1.0$ \\
\hline
\end{tabular}

this habitat. A phylogenetic analysis demonstrated that the five isolates represented a unique lineage within the phylum Firmicutes, with E. desmolans ATCC $43058^{\mathrm{T}}$ as the closest phylogenetic neighbour. These data indicate that the five novel isolates represent a single novel species within a novel genus, for which the name Butyricicoccus pullicaecorum gen. nov., sp. nov. is proposed.

The closest phylogenetic neighbour, E. desmolans, can be readily distinguished from $B$. pullicaecorum sp. nov. on the basis of biochemical criteria. In contrast to B. pullicaecorum, E. desmolans does not ferment cellobiose, aesculin, glucose, maltose, mannose or trehalose. Reclassification of $E$. desmolans as a member of the genus Butyricicoccus cannot be considered, as there is only $93 \% 16 \mathrm{~S}$ rRNA gene sequence similarity between the two type strains and their $\mathrm{G}+\mathrm{C}$ contents are very different $(35 \mathrm{~mol} \%$ for E. desmolans ATCC $43058^{\mathrm{T}}$ versus $54.5 \mathrm{~mol} \%$ for $B$. pullicaecorum $23-5^{\mathrm{T}}$ ).

\section{Description of Butyricicoccus gen. nov.}

Butyricicoccus (Bu.ty.ri'ci.coc'cus. N.L. n. acidum butyricum butyric acid; N.L. masc. n. coccus a coccus; N.L. masc. n. Butyricicoccus coccoid-shaped bacterium that produces butyrate).

Cells are Gram-positive, anaerobic, non-motile, coccoid and usually arranged in pairs (occasionally in short chains). Produce butyrate, $\mathrm{H}_{2}$ and $\mathrm{CO}_{2}$ and utilize acetate in M2GSC broth. The phylogenetic position is in a novel lineage in the class Clostridia of the phylum Firmicutes. The type species is Butyricicoccus pullicaecorum.

\section{Description of Butyricicoccus pullicaecorum sp. nov.}

Butyricicoccus pullicaecorum (pul.li.cae.co' rum. L. n. pullus a chicken; L. n. caecum caecum; L. gen. pl. n. caecorum of caeca; N.L. gen. pl. n. pullicaecorum of the caeca of chickens).

Displays the following properties in addition to those described for the genus. Cells are approximately $1.2-$ $1.5 \mu \mathrm{m}$ long. On M2GSC agar after $24 \mathrm{~h}$ at $42{ }^{\circ} \mathrm{C}$, colonies are white, smooth, circular and $1-2 \mathrm{~mm}$ in diameter. All five known isolates hydrolyse aesculin and ferment glucose, salicin, sucrose, maltose, xylose, cellobiose, mannose and trehalose. Urease activity, gelatin hydrolysis and fermentation of mannitol, lactose, arabinose, glycerol, melezitose, raffinose, sorbitol and rhamnose are absent. The $\mathrm{G}+\mathrm{C}$ content of genomic DNA of the type strain is $54.5 \mathrm{~mol} \%$. The type strain, $25-3^{\mathrm{T}}\left(=\mathrm{LMG} 24109^{\mathrm{T}}=\right.$ CCUG $\left.55265^{\mathrm{T}}\right)$, was isolated in Ghent (Belgium) in 2007 from the caecal content of a 4-week-old broiler chicken.

\section{Acknowledgements}

We thank Sjaraï Deschildre, Arlette Van de Kerckhove and Sofie Callens for their skilful technical assistance. We also thank Wim Van Den Broeck and Bart De Pauw of the Department of Morphology, Faculty of Veterinary Medicine, Ghent University, for scanning electron microscopy. Dr J. P. Euzéby is acknowledged for advice on the species name and Latin usage. This work was funded by the Belgian Federal Public Service for Health, Food Chain Safety and Environment. F.V.I. is a post-doctoral fellow of the Research Foundation - Flanders (FWO). The Rowett Research Institute receives support from the Scottish Government.

\section{References}

Apajalahti, J., Kettunen, A. \& Graham, H. (2004). Characteristics of the gastrointestinal microbial communities, with special reference to the chicken. Worlds Poult Sci J 60, 223-232.

Barcenilla, A., Pryde, S. E., Martin, J. C., Duncan, S. H., Stewart, C. S., Henderson, C. \& Flint, H. J. (2000). Phylogenetic relationships of butyrate-producing bacteria from the human gut. Appl Environ Microbiol 66, 1654-1661.

Coenye, T., Falsen, E., Vancanneyt, M., Hoste, B., Govan, J. R. W., Kersters, K. \& Vandamme, P. (1999). Classification of Alcaligenes faecalis-like isolates from the environment and human clinical samples as Ralstonia gilardii sp. nov. Int J Syst Bacteriol 49, 405-413.

Coenye, T., Spiker, T., Martin, A. \& LiPuma, J. J. (2002). Comparative assessment of genotyping methods for epidemiologic study of Burkholderia cepacia genomovar III. J Clin Microbiol 40, 3300-3307.

Collins, M. D., Lawson, P. A., Willems, A., Cordoba, J. J., FernandezGarayzabal, J., Garcia, P., Cai, J., Hippe, H. \& Farrow, J. A. E. (1994). The phylogeny of the genus Clostridium: proposal of five new genera and eleven new species combinations. Int J Syst Bacteriol 44, 812-826.

Felsenstein, J. (1989). PHYLIP - phylogeny inference package (version 3.2). Cladistics 5, 164-166.

Kien, C. L., Blauwiekel, R., Bunn, J. Y., Jetton, T. L., Frankel, W. L. \& Holst, J. J. (2007). Cecal infusion of butyrate increases intestinal cell proliferation in piglets. $J$ Nutr 137, 916-922.

Kimura, M. (1980). A simple method for estimating evolutionary rates of base substitutions through comparative studies of nucleotide sequences. J Mol Evol 16, 111-120.

Lan, P. T. N., Hayashi, H., Sakamoto, M. \& Benno, Y. (2002). Phylogenetic analysis of cecal microbiota in chicken by the use of $16 \mathrm{~S}$ rDNA clone libraries. Microbiol Immunol 46, 371-382.

Miyazaki, K., Martin, J. C., Marinsek-Logar, R. \& Flint, H. J. (1997). Degradation and utilization of xylans by the rumen anaerobe Prevotella bryantii (formerly $P$. ruminicola subsp. brevis) $\mathrm{B}_{1} 4$. Anaerobe 3, 373-381.

Morris, G. N., Winter, J., Cato, E. P., Ritchie, A. E. \& Bokkenheuser, V. D. (1986). Eubacterium desmolans sp. nov., a steroid desmolaseproducing species from cat fecal flora. Int J Syst Bacteriol 36, 183-186. 
Pearson, W. R. \& Lipman, D. J. (1988). Improved tools for biological sequence analysis. Proc Natl Acad Sci U S A 85, 2444-2448.

Pryde, S. E., Duncan, S. H., Hold, G. L., Stewart, C. S. \& Flint, H. J. (2002). The microbiology of butyrate formation in the human colon. FEMS Microbiol Lett 217, 133-139.

Richards, S. A. (1970). The role of hypothalamic temperature in the control of panting in the chicken exposed to heat. J Physiol 211, 341-358.

Saitou, N. \& Nei, M. (1987). The neighbor-joining method: a new method for reconstructing phylogenetic trees. Mol Biol Evol 4, 406-425.

Thompson, J. D., Higgins, D. G. \& Gibson, T. J. (1994). CLUSTAL W: improving the sensitivity of progressive multiple sequence alignment through sequence weighting, position-specific gap penalties and weight matrix choice. Nucleic Acids Res 22, 4673-4680.

Van Immerseel, F., Boyen, F., Gantois, l., Timbermont, L., Bohez, L., Pasmans, F., Haesebrouck, F. \& Ducatelle, R. (2005).
Supplementation of coated butyric acid in the feed reduces colonization and shedding of Salmonella in poultry. Poult Sci 84, 1851-1856.

Van Nevel, C. J. \& Demeyer, D. I. (1977). Effect of monensin on rumen metabolism in vitro. Appl Environ Microbiol 34, 251-257.

Van Nevel, C. J., Demeyer, D. I., Henderickx, H. K. \& Martin, J. A. (1970). A simple method for the simultaneous determination of gas production and volatile fatty acid concentration in the rumen. $Z$ Tierphysiol Tierernahr Futtermittelkd 26, 100-104.

Versalovic, J., Scheider, M., de Bruijn, F. J. \& Lupski, J. R. (1994). Genomic fingerprinting of bacteria using repetitive sequence-based polymerase chain reaction. Methods Mol Cell Biol 5, 25-40.

Weisburg, W. G., Barns, S. M., Pelletier, D. A. \& Lane, D. J. (1991). $16 \mathrm{~S}$ ribosomal DNA amplification for phylogenetic study. J Bacteriol 173, 697-703. 